\title{
Midwives' Professional Competency for Preventing Neonatal Mortality in Disasters
}

\author{
Ziba Taghizadeh ${ }^{1}$, Mahsa Khoshnam Rad ${ }^{2 *}$, Anushirvan Kazemnejad \\ 1. Departments of Reproductive Health, Faculty of Nursing and Midwifery, Tehran University of Medical Sciences, Tehran, Iran. \\ 2. Departments of Midwifery, Faculty of Nursing and Midwifery, Tehran University of Medical Sciences, Tehran, Iran. \\ 3. Departments of Biostatics, School of Medical Sciences, Tarbiat Modares University, Tehran, Iran.
}

Citation: Taghizadeh Z, Khoshnam Rad M, Kazemnejad A. Midwives' professional competency for preventing neonatal mortality in disasters. Health in Emergencies and Disasters Quarterly. 2016; 1(3):155-162. http://dx.crossref.org/10.15412/J.HDQ.09010306

dol: $:$ http://dx.crossref.org/10.15412/J.HDQ.09010306

Article info:

Received: 29 Sep. 2015

Accepted: 7 Feb. 2016

\section{Keywords:}

Reproductive health services, Disasters, Neonatal mortality, Midwife, Professional competency

\section{A BSTRACT}

Background: Infants are the most vulnerable people with special needs in natural disasters. Since midwives are responsible for providing reproductive health services to infants in disastrous situations, assessing their professional competence is of great importance.

Materials and Methods: This cross-sectional study was conducted in Tehran, Iran. A total of 361 midwives were selected by cluster sampling method. After giving their informed consents, they participated in the study and completed the researcher-made questionnaire about providing health services to infants in natural disasters. Midwives' professional competence was investigated through self-assessment in terms of their perceived importance, knowledge, and skill. Then, the data were analyzed using SPSS.

Results: Mean(SD) total score of professional competency of midwives in providing services to infants in disasters was 91.95(20.2) obtained from 3 subcategories: perceived importance, 39.83(9.55); knowledge, 22.5(5.06); and skill 30.16(6.86). There were significant relationships between the scores of professional competency of midwives with age $(\mathrm{P}=0.053)$, degree of education ( $\mathrm{P}=0.028)$, the workplace $(\mathrm{P}=0.053)$, and experience in disaster $(\mathrm{P}=0.047)$. About $49.86 \%$ of midwives demonstrated middle level of professional competency. The lowest knowledge and skill score were reported in managing common neonatal problems such as asphyxia, sepsis, physical trauma, which requires referral and stability.

Conclusion: The average scores of professional competency of midwives to deliver reproductive health service to infants in disasters shows the necessity of related and integrated education. It is recommended that by holding training exercises and simulations, midwives be educated with regard to disasters and how to respond in these situations.

\footnotetext{
* Corresponding Author: 


\section{Introduction}

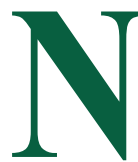

atural disasters happen suddenly and need urgent responses. In emergency situations, the lives of many people are compromised, famine and displacement may occur, and dead toll rises. Therefore, the essential health care services must be delivered to the affected population. This is not possible without the help of the health service providers [1]. In this regard, one of the areas of interest is presenting the reproductive health services [2].

Women, pregnant and breast feeding mothers, infants and children under 5, elderly and disabled people are the vulnerable groups in disasters. Infants and children under 5 are the most vulnerable groups and are highly sensitive to the poor conditions and lack of health care and nutrition so that if they do not receive necessary care, they will suffer from severe health problems. Reportedly, most of the death toll is related to this group so that $75 \%$ of the infants born during disasters lose their lives before their second-year birthday [3]. The main reasons of the newborn babies' deaths at the time of the disasters are asphyxia, infections, prematurity, tetanus, and low body temperature which implies their special needs. These problems are largely preventable by providing essential midwifery care [4]. Hence, the midwives' roles in this regard are very crucial. The importance of protecting and caring for newborns requires the presence of a midwife as a provider of health services to mothers and infants. Midwives, as the first providers of reproductive health services, are educated to answer the reproductive health needs. Therefore, they must possess sufficient professional competence [5].

Professional competence means all knowledge, skills, and competencies which are relevant for the proper function in an unexpected situation. Evaluation of people's professional competency in response to the disastrous situations is essential and regarded as the first step in preparing the health care providers [6]. Determining the current competence of healthcare members in decisionmaking and effective planning is important. The proper evaluation of their professional competency could be the basis for education and evidence-based education [7]. The World Health Organization has considered the lack of studies in this field as one of the main concerns and emphasized on its importance in developing countries because they are more prone to disasters. Newbrander et al. stated that in the area of reproductive health and care of newborns and mothers, few studies have been conducted [8]. Our country has always been faced with earthquakes and floods and experienced many years of wars. Because few studies have been done about mid- wifery care of babies in disasters and researchers have found few related studies in this area, this study aimed to investigate the midwives' professional competency to prevent the newborns' deaths.

\section{Materials and Methods}

This cross-sectional study was conducted in Tehran, Iran, in 2014. Study participants comprised midwives working in hospitals. A sample with $95 \%$ confidence interval and taking into account of 5.1 points was calculated.

According to the study of the sample size by Putra et al. [9] entitled "the study of the Indonesian perceived nurses' ability in disaster", the amount S was extracted in this study.

Because the objective of this study was to evaluate the professional competency of midwives in Tehran, we used cluster sampling method to create sufficient dispersion and uniform distribution of the sample.

$$
\begin{gathered}
n=\frac{\mathrm{z}_{1-\alpha}^{2} \times \mathrm{S}_{2}}{\mathrm{~d}^{2}}=\frac{1.96^{2} \times 13.27^{2}}{1.5^{2}}=300.6 \cong 301 \\
301+30 \times 0.20=361
\end{gathered}
$$

The number of samples was 361 midwives. Midwives inclusion criteria were as follows: having a degree in midwifery, having at least 6 months experience in one of the public hospitals in the city, and a desire to participate in the study. Those who did not complete about $15 \%$ of the questionnaire items were decided to be excluded from the study; however, all participants remained in the study. The researcher visited the centers for easy and available sampling, and included all the midwives in the study as much as possible. After explaining the objectives of the study and obtaining the midwives' informed consents, the researcher gave them the questionnaires. The midwives returned the completed questionnaires to the researcher in the same shift or later by the phone calls.

The participants completed the researcher-made questionnaire as "professional competency to provide reproductive health services in disasters to prevent the infant deaths". The questionnaire was designed based on the questionnaire used in the Veras et al. study [10] that examined the professional competency of medical professionals. It is a self-assessment measurement of the 3 components of the perceived importance, knowledge, and skills. However, the questionnaire original 
items were revised based on the objective of this study and the literature review of the resources associated with the goals of MISP (Minimum package of the reproductive health services in disasters). We tried to extract the most important causes of morbidity and mortality of the infants from the literature. A total of 10 items were chosen and considered as the questionnaire items. Then, the midwives self-assessed their professional competency based on the questionnaire items.

Veras et al. questionnaire is reliable instrument and used by various researchers in different countries such as Canada, America, Germany, and Korea for different objectives. Therefore, the method of scoring was based on this questionnaire. In this way, the midwives under the study in response to each item, in the perceived importance section, evaluated the importance level of the services for the babies based on the midwives' perspectives, in 5 scores (it does not matter at all=1, it is a little impor$\tan t=2$, it is fairly important $=3$, it is important $=4$, and it is very important $=5$ ). In knowledge section, they evaluated their level of knowledge with the help of 3 scores (I have no knowledge at all $=1$, I have a little knowledge $=2$, and I have enough knowledge=3). Finally, they evaluated their skill in 5 scores from "I have no skill"=1 to "I have a complete skill"=5 like the importance section.

The obtained score in importance section ranged from 10 to 50 , in knowledge section from 10 to 30 , in skill section from 10 to 50 , and the total score for professional competence ranged from 30 to 130 . According to similar studies in this area [10], 4 levels from weak to strong were proper for the classification of scores and could define the professional competence. Therefore, the range of the total professional competence (30-130) was classified in 4 levels including: very weak: scores from 30 to 54, weak: scores from 55 to 79, average: scores from 80 to 104, strong: scores from 105 to 130 . The cutoff points were selected in such a way that creates 4 equal levels and at every level 25 points can be placed.

Then, the sum of the individuals in percentage term was calculated, in the high and very high perceived importance (those who expressed the high or very high perceived importance) as the ones who have a proper perceived importance, in the knowledge column, as the ones with proper knowledge, and in the high and very high skill column, as the proper skill. And, they are considered as the ones who possess the proper professional competence to compare professional competency of midwives, according to the items of the questionnaire.
To evaluate the instruments' validity, the questionnaire was given to the 15 faculty members of the Nursing and Midwifery School of Tehran University. Five of the midwives were members of Tehran Red Crescent. After receiving comments from midwives and faculty members, the questionnaire items were reviewed. For analyzing the questionnaire reliability, the Cronbach coefficient $\alpha$ was calculated with 0.95 .

The data were analyzed by using SPSS, version 17 . The analyses included descriptive and analytical statistics such as ANOVA, t-test and correlation test at a significance level $\mathrm{P}<0.05$.

\section{Results}

The midwives' mean(SD) age was 32.8(9.18) years. The most frequent age group was 20-30 years (8.57\%). Most of participated midwives in this study $(74.1 \%)$ had a BS in Midwifery and midwifery doctoral students and technicians comprised about $3 \%$ of the sample.

The highest percentage of midwives (6.49\%) had participated in the study from the maternity hospitals. The minimum work experience was less than 1 year and the maximum was 34 years. The majority of midwives $(26 \%)$ who work in the hospitals graduated from Tehran University, but generally the participated midwives in this study graduated from universities all over the country. Only $3.18 \%$ of the participants in the study had experienced the presence in any disasters of which $44 \%$ of them evaluate their performance well and $7.16 \%$ were poor. About $30.4 \%$ of midwives mentioned that they had been trained previously about disasters. And, $74.6 \%$ of the participants stated that university education has not prepared them for the proper functioning in disasters. Midwives were asked to comment on proper teaching method to acquire preparation for an effective role in disasters. Also, 29.2\% of them commented on related content integration, $10 \%$ on regular workshops, and $19.4 \%$ on both. Practical training, disaster simulation, film screenings, and short-term training courses in deprived areas were midwives' other suggestions.

The mean(SD) professional competency of midwives for the prevention of newborn deaths in perceived importance was 39.83(9.55), in knowledge was 22.5 and in skills was $86.6(16.30)$.

The mean(SD) professional competency of midwives for the prevention of newborn deaths was found with regard to perceived importance as 55.9(83.39), knowledge as 06.5(5.22) and skills as 86.6(16.30). The overall aver- 


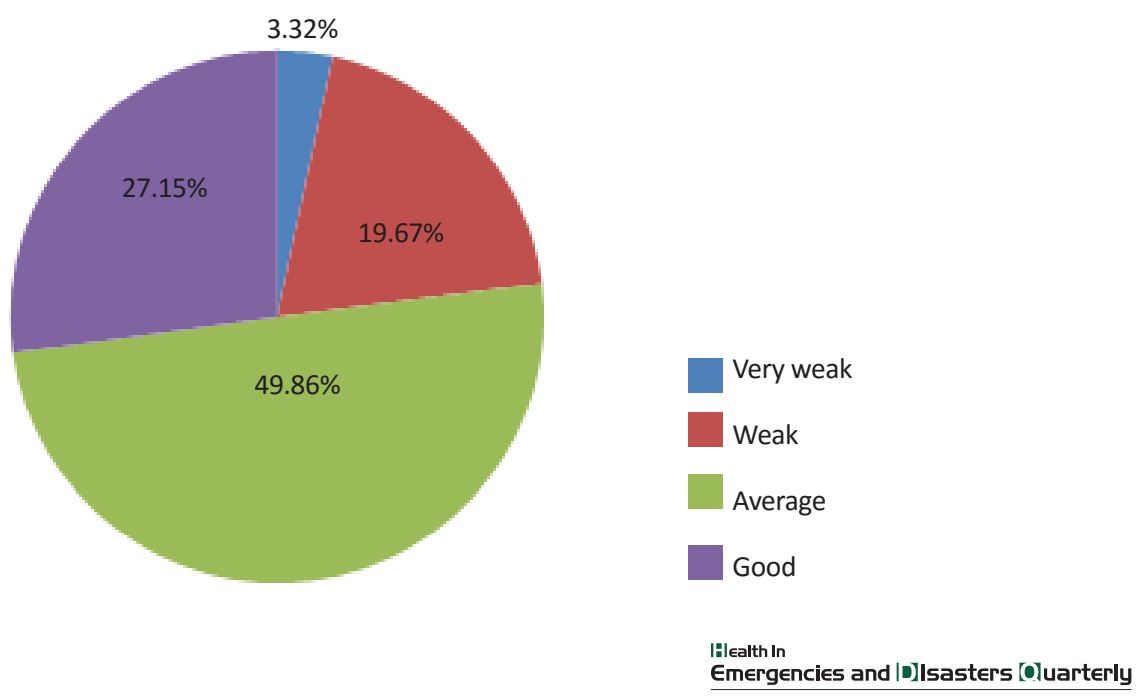

Figure 1. The level of the midwives' professional competency in presenting reproductive health care for infants.

age score for professional competency of midwives was found as 2.20(95.91) for babies' services.

Most midwives (49.86\%) demonstrated average professional competency in preventing the infants' deaths in disasters (Figure 1).

Midwives reported the least amount of knowledge with regard to "interventions in babies with physical hurt". Only $28.3 \%$ had sufficient knowledge and lowest score were in the "interventions in babies with physical injury", "diagnosis and care of infected babies," and "babies need a referral diagnosis" cases (4.22\% had strong skills).

Midwives often had a proper perceived importance of disaster in infants' care (Table 1). According to the above table, the lowest perceived importance belonged to "stabilizing the situation in infants' referral" and the least amount of knowledge and skills of midwives belonged to "interventions in newborns suffered from physical hurt".

Table 1. Professional competency of midwives (perceived importance, knowledge, and skills) in each item to prevent infant death in disasters.

\begin{tabular}{|c|c|c|c|c|}
\hline & Questionnaire items & $\begin{array}{l}\text { Perceived impor- } \\
\text { tance }(\%)\end{array}$ & $\begin{array}{l}\text { Adequate knowledge } \\
\text { (\%) }\end{array}$ & Proper skill (\%) \\
\hline 1 & $\begin{array}{l}\text { Knowledge of the process of the } \\
\text { infants' resuscitation }\end{array}$ & 82.3 & 55.8 & 43.2 \\
\hline 2 & Prevention of hypothermia & 83.3 & 67.6 & 56 \\
\hline 3 & $\begin{array}{c}\text { Diagnosis and care of babies with } \\
\text { asphyxia }\end{array}$ & 78.9 & 37.7 & 31.4 \\
\hline 4 & $\begin{array}{l}\text { Diagnosis and care of newborns with } \\
\text { infection }\end{array}$ & 77.6 & 31.5 & 24.4 \\
\hline 5 & Infant feeding practices in disaster & 78.3 & 48.8 & 36.1 \\
\hline 6 & $\begin{array}{l}\text { Diagnosis and management of umbili- } \\
\text { cal cord infection and neonatal tetanus }\end{array}$ & 80.7 & 48.8 & 40.2 \\
\hline 7 & Vaccination of infants in disasters & 78.6 & 46.1 & 40 \\
\hline 8 & $\begin{array}{l}\text { Physical interventions in the neonatal } \\
\text { injury }\end{array}$ & 73.8 & 28.3 & 22.8 \\
\hline 9 & $\begin{array}{l}\text { Stabilizing the situation in neonatal } \\
\text { referral }\end{array}$ & 72.7 & 32.1 & 29.7 \\
\hline 10 & $\begin{array}{l}\text { Identify babies who need } \\
\text { referral }\end{array}$ & 75.2 & 32.8 & 24.4 \\
\hline
\end{tabular}


Table 2. Factors related to professional competency of midwives.

\begin{tabular}{|c|c|c|c|c|}
\hline Related factors & Number & Percentage & $\begin{array}{l}\text { Professional compe- } \\
\text { tency scores (Mean } \\
\pm \mathrm{SD} \text { ) }\end{array}$ & Significance level (P) \\
\hline \multirow[b]{2}{*}{ Previous education } & Yes & 110 & $95.67 \pm 18.9$ & \multirow[b]{2}{*}{0.88} \\
\hline & & 251 & $90.89 \pm 19.6$ & \\
\hline \multirow{2}{*}{ Experience in disasters } & Yes & 66 & $23.8 \pm 96.2$ & \multirow{2}{*}{0.047} \\
\hline & No & 295 & $19.3 \pm 91.1$ & \\
\hline \multirow{4}{*}{ Degree of education } & Associate & 11 & $85.5 \pm 24.4$ & \multirow{4}{*}{0.028} \\
\hline & BA & 262 & $91.3 \pm 19.6$ & \\
\hline & MS & 70 & $94.2 \pm 21.2$ & \\
\hline & $\mathrm{PhD}$ & 11 & $108.8 \pm 9.27$ & \\
\hline \multirow{6}{*}{ Working ward } & Accouchement & 179 & $93.26 \pm 1.5$ & \multirow{6}{*}{0.053} \\
\hline & Postpartum & 47 & $83.50 \pm 2.8$ & \\
\hline & Prenatal & 20 & $89.84 \pm 3.3$ & \\
\hline & Women & 45 & $92.37 \pm 2.9$ & \\
\hline & Infants & 22 & $91.54 \pm 4.4$ & \\
\hline & other & 48 & $93.15 \pm 2.7$ & \\
\hline
\end{tabular}

There were significant relationships between the scores of professional competency of midwives and variables of age $(\mathrm{P}=0.053)$, degree of education $(\mathrm{P}=0.028)$, the working ward $(\mathrm{P}=0.053)$, and experience in disaster $(\mathrm{P}=0.047)$.

But there were no significant relationships between midwives' professional competency and variables of the history of midwifery $(\mathrm{P}=0.152)$ and having previous training $(\mathrm{P}=0.88)$ about the disaster (Table 2$)$.

\section{Discussion}

The results of this study showed that midwives have an average competence in providing health reproductive services to infants. This moderate competence can be due to inadequate training as the majority of them $(69.6 \%)$ noted that they had never been trained about this issue and the academic training was not effective in preparing them. The absence of any relation between the previous disaster training and the midwives professional competency can be due to the fact that the current trainings are limited or are not specific to the reproductive health services. Therefore, it seems that the criterion and the presentation of trainings must be revised. Because the participant midwives in this study have graduated from different universities all around the country, we can conclude that the midwives have not received adequate academic training to be prepare for an effective role in disasters not only in Tehran, but also in other cities of the country.

Of course, this issue is being considered in other parts of the world. Although the principles of MISP has been considered since 1996 and midwives play an important role in the implementation of its principles, there has not been any coherent planning in their professional competency improvement [11]. In this study, the history of midwifery had no significant relationship with professional competency. In Buck et al. study, the working experience at the city hospitals did not affect the perceived competence of the nurses in the disasters [12]. However, the professional competency of midwives who work in the maternity ward was more which could be due to the nature of this work in this ward that midwives mostly need the skills and the knowledge related to the infants and the childbirth. Also, those midwives who were older and had more experiences in facing disasters stated more professional competency. Probably, the experience of the conditions of the perceived importance had increased the midwives' skills. Previous exposure to disaster in Putra (2011) also caused more report on the perceived importance. He stated that the presence in the disastrous situations either real or through simulation exercises was needed for preparation [9]. 
The under-study midwives cited the need to integrate the related reproductive health services in disaster in university curriculum and the use of techniques such as simulation for their preparation. In Su study in China, most health professionals noted the effectiveness of lectures, effective educational practice, and training courses in disasters [13]. Evidently, the good performance of health professionals in disasters is needed and creating opportunities for learning and the evaluation of the perceived skills in simulated environment is growing [14]. Furthermore, education and training for active participation and presence in disasters is recommended for an increase in skill and perceived knowledge [11].

Midwives did not report adequate knowledge and skill in managing common infants' problems in disasters such as infections and malnutrition. Because educational programs should be presented according to health service providers' professional needs in disasters to create a sound scientific background and skill, we feel the need for specific planning in these areas for midwives. A large proportion of the infants' deaths in disasters are due to problems such as malnutrition, diarrhea, and poor nutrition which are easily preventable by education and preparation. The after-war study results showed that $89 \%$ of the infants' deaths was related to the preventable diseases such as diarrhea which was directly due to absence of the health workers. Therefore, with proper training and promoting the professional competency in midwives, the consequent infants' deaths in disasters can be prevented. Although the importance of midwives' role and other reproductive health professionals is obvious and some guidelines on newborn care in disasters have been prepared, the training and the education which are presented to midwives are inadequate [3].

The referral and convenient transportation system in disasters is one of the main needs of the medical team and the affected population [15]. Unfortunately, midwives in this study demonstrated very low competency in the process of the diagnosis and the referral of the infants. According to a study in America, after Katrina Hurricane, 120 ill infants and 154 mothers were referred to hospitals. Some of these babies were without their mothers and it took 10 days to reach to their mothers [16]. Thus, a midwifery care team in disasters must be well prepared in responding to the needs of both mother and baby at the same time and dispatching them into more equipped centers. In many resources, midwives are emphasized as the first lines in facing the crisis and the needs of the infants. Midwives' preparation in presenting reproductive health care is a valuable asset not only in our country but also in neighboring countries, which are threatened by disasters and dealt with the human-made disasters such as war. Finally, it seems that more studies are needed is this area.

\section{Conclusion}

Despite the vulnerability of infants and their special needs in disasters, midwives of Tehran demonstrated average professional competency to provide reproductive health services. Lack of up-to-date training, lack of knowledge, and low-skilled midwives highlight the necessity of planning priorities. Preparing midwives for managing the common infants' problems need sufficient and related training.

\section{Research Limitations}

Our study method was self-assessment, which is not an appropriate method to evaluate the professional competence of midwives. A good evaluation also needs to examine objective and practical skills.

\section{Acknowledgments}

This research is the result of a MS thesis, code No. 9111373017 registered at Tehran University of Medical Sciences, Nursing and Midwifery School. The researchers would like to thank the related members at Tehran University of Medical Sciences for their financial support, and all midwives who participated in this study and sincerely helped us in the process of data collecting.

\section{Conflict of Interests}

The authors declared no conflict of interests.

\section{References}

[1] Bella Magnaye RN, Muñoz MS, Muñoz MA, Muñoz RG, Muro JH. The role, preparedness and management of nurses during disasters. International Scientific Research Journal. 2011; 3(4):269-94

[2] Tanabe M, Schaus K, Rastogi S, Krause SK, Patel P. Tracking humanitarian funding for reproductive health: a systematic analysis of health and protection proposals from 2002-2013. Conflict and Health. 2015; 9(1):S2. doi: 10.1186/1752-1505-9S1-S2

[3] Sulaiman Z, Mohamad N, Ismail TA, Johari N, Hussain NH. Infant feeding concerns in times of natural disaster: lessons learned from the 2014 flood in Kelantan, Malaysia. Asia Pacific Journal of Clinical Nutrition. 2015; 25(3). doi: 10.6133/ apjen.092015.08 
[4] Davanzo R. Newborns in adverse conditions: issues, challenges, and interventions. Journal of Midwifery \& Women's Health. 2004; 49(1):29-35. doi: 10.1016/j.jmwh.2004.05.002

[5] Giarratano G, Sterling YM, Orlando S, Mathews P, Deeves G, Bernard ML, et al. Targeting prenatal emergency preparedness through childbirth education. Journal of Obstetric, Gynecologic, \& Neonatal Nursing. 2010; 39(4):480-88.

[6] Slepski LA. Emergency preparedness and professional competency among health care providers during hurricanes Katrina and Rita: pilot study results. Disaster Management \& Response. 2007; 5(4):99-110.

[7] World Health Organization. ICN framework of disaster nursing competencies. Geneva: World Health Organization; 2009.

[8] Newbrander W, Waldman R, Shepherd-Banigan M. Rebuilding and strengthening health systems and providing basic health services in fragile states. Disasters. 2011; 35(4):63960.

[9] Putra A, Petpichetchian W, Maneewat K. Perceived ability to practice in disaster management among public health nurses in Aceh, Indonesia. Nurse Media Journal of Nursing. 2011; 1(2):169-86

[10] Veras M, Pottie K, Welch V, Labonte R, Eslava-Schmalbach J, Borkhoff CM, et al. Reliability and validity of a new survey to assess global health competencies of health professionals. Global Journal of Health Science. 2013; 5(1):13 -27. doi 10.5539/gihs.v5n1p13

[11] Onyango MA, Hixson BL, McNally S. Minimum Initial Service Package (MISP) for reproductive health during emergencies: time for a new paradigm? Global Public Health. 2013; 8(3):342-56.

[12] Baack S, Alfred D. Nurses' preparedness and perceived competence in managing disasters. Journal of Nursing Scholarship. 2013; 45(3):281-87.

[13] Su T, Han X, Chen F, Du Y, Zhang H, Yin J, et al. Knowledge levels and training needs of disaster medicine among health professionals, medical students, and local residents in Shanghai, China. PloS One. 2013; 8(6):67041. doi: 10.1371/ journal.pone.0067041

[14] Arnold JJ, Johnson LM, Tucker SJ, Malec JF, Henrickson SE, Dunn WF. Evaluation tools in simulation learning: Performance and self-efficacy in emergency response. Clinical Simulation in Nursing. 2009; 5(1):35-43.

[15] Tucker J, Hundley V, Kiger A, Bryers H, Caldow J, Farmer J et al. Sustainable maternity services in remote and rural Scotland? A qualitative survey of staff views on required skills, competencies and training. Quality and Safety in Health Care. 2005; 14(1):34-40

[16] Jorgensen AM, Mendoza GJ, Henderson JL. Emergency preparedness and disaster response core competency set for perinatal and neonatal nurses. Journal of Obstetric, Gynecologic, \& Neonatal Nursing. 2010; 39(4):450-67. 
